\title{
Early Maladaptive Schemas and Perceived Parental Rearing Behaviors in Korean Depressed Subjects
}

\author{
Jieun Kwon, Soontaeg Hwang, Seungbok Lee \\ Chungbuk National University, Chungju, Korea
}

\begin{abstract}
In this paper, the EMSs (early maladaptive schemas) and the perceived PRBs (parental rearing behaviors) in depressed subjects have been studied. Also, the perceived PRBs known to be one of the origins of the depression-predicting maladaptive schema have been studied. YAQ (Young Schema Questionnaire)—Korean short version, inventory for perceived PRBs and BDI (Beck Depression Inventory) have been surveyed to 240 university students. The results are summarized as follows: (1) "defectiveness/shame", "vulnerability to harm or illness", "failure" and "social isolation/alienation" among 18 maladaptive schemas are shown to be the predicting variables corresponding to $59 \%$ of the total depression variables; and (2) "neglect" and "intrusiveness" of the perceived PRBs are the predicting variables corresponding to $20 \%-27 \%$ of the total variables of "disconnection and rejection" and "impaired autonomy and performance" schema domains to which the depression predicting schemas belong. The meaning and limitation of this study and the suggestion for the further study are discussed.
\end{abstract}

Keywords: maladaptive schema, depression, perceived parental rearing behaviors

Depression is a typically recurrent or chronic disorder (Andrade et al., 2003; Kessler et al., 2003). Accordingly, more knowledge about vulnerability factors for depression is of major importance in order to prevent and treat depression.

From a cognitive perspective, distal vulnerability factors may represent developmental antecedents, such as negative self-schemas, whereas proximal vulnerability factors, which are partly based on the distal vulnerability, may reflect cognitive dispositions, such as negative automatic thoughts (Ingram \& Siegle, 2002). In Beck's $(1967 ; 1987)$ cognitive theory of depression, negative self-schemas are a key vulnerability factor.

Young, Klosko, and Weishaar (2003) elaborated on the schema concept. Young regarded the development of knowledge structures concerning ourselves through interaction with the social environment as the most important. More specifically, according to Young (1990), a child's enduring experience of not getting his/her basic emotional needs met in relationships with significant others will give rise to the development of EMSs (early maladaptive schemas). The EMSs refer to the deepest level of cognitive structures and are defined as self-defeating emotional and cognitive patterns regarding oneself and one's personal relationships (Young et al., 2003). Young et al. (2003) hypothesized that there are 18 core maladaptive schemas, which can be allocated in five schema domains: disconnection and rejection, which contains the schemas of: (1) emotional deprivation, (2) abandonment, (3) mistrust and abuse, (4) social isolation and alienation, and (5) defectiveness and shame; impaired autonomy and

Jieun Kwon, Ph.D. candidate, Department of Psychology, Chungbuk National University.

Soontaeg Hwang, Ph.D., professor, Department of Psychology, Chungbuk National University.

Seungbok Lee, Ph.D., professor, Department of Psychology, Chungbuk National University. 
performance, which consists of the schemas of: (6) dependence and incompetence, (7) vulnerability to harm or illness, (8) enmeshment, and (9) failure to archive; impaired boundaries, which is concerned with the schemas of: (10) entitlement and grandiosity, and (11) insufficient self-control and self-discipline; orientation towards others, which pertains to the schemas of: (12) subjugation, (13) self-sacrifice, and (14) seek recognition/permission; excessive control, which has to do with the schemas of: (15) pessimistic, (16) emotional inhibition, (17) unrelenting standards, and (18) punishment. Five schema domains are relevant to unmet emotional needs related to core themes, such as autonomy and intimacy (Schmidt, Joiner, Young, \& Telch, 1995).

The key assumption of the schema theory is that the EMSs play a causal role in the development of psychopathology including depression. To assess the schema domains and allied core maladaptive schemas, Young and Brown (1990) developed the YSQ (Young Schema Questionnaire). Using the YSQ, core maladaptive schemas have been successfully identified in patients suffering from various types of psychopathology such as eating disorders (Meyer \& Gillings, 2004; Waller, Dickson, \& Ohanian, 2002), anxiety disorders (Dellatre et al., 2004), comorbid anxiety and eating disorders (Hinrichsen, Waller, \& Emanuelli, 2004; 2006) and aggression-related disorders (Baker \& Beech, 2004).

EMSs are generally assumed that they are installed during childhood as a result of a combination of an inherited vulnerable temperament (in particular neuroticism) and dysfunctional experiences with parents, siblings and peers. These schemas are not the result of isolated traumatic incidents, but rather the product of enduring patterns of toxic interactions with family members and peers (Young, 1994). Many studies have actually examined the notion that maladaptive schemas are formed during childhood (Bosmans, Braet, \& Vlierberghe, 2009; Harris \& Curtin, 2002; McGinn, Cukor, \& Sanderson, 2005; Muris, 2006; Soygüt \& Çakir, 2009; Wright, Crawford, \& Del Castillo, 2009). Bosmans et al. (2009) suggested that the early maladaptive schemas can be regarded as providing a very tangible insight in the rich contents of the maladaptive cognitions underlying the attachment system. The study of Cukor (2004) investigated the links between retrospectively perceived parental rearing styles and cognitive schemas. The results suggested that poor parenting practices were associated with the presence of maladaptive schemas. These findings are in keeping with Young's (1994) notion that a poor home environment promotes the formation of maladaptive schemas, which in turn make the individual vulnerable to develop various types of psychological disorder. But few studies have actually examined the notion that maladaptive schemas are formed during childhood.

In this study, we investigated: (1) which maladaptive schema is associated with the depression; and (2) which detrimental PRB affects the maladaptive schema domains associated with the depression.

\section{Method}

\section{Participants}

Participants were 300 undergraduate students with mean age of $22.82(S D=2.9)$. All the participants were Korean in the region of Chungbuk Korea. Uncompleted data were excluded, so 240 data of participants (114 men and 126 women) were analyzed. Participants received the result that they had responded measures via E-mail.

\section{Questionnaires}

\section{BDI (Beck Depression Inventory)}

The BDI is composed of 21 items rated on four-Likert scale ranging from zero to three, based on severity 
of each item. The total score of BDI is matched with established degrees of depression: minimal, mild, moderate, moderate to severe and severe. In this study, the Korean version of BDI (Lee \& SONG, 1991) was used. In the present study, Cronbach's alpha was 0.90 .

\section{YSQ}

The YSQ (Young \& Brown, 1994) is a 205-item self-report inventory rated on six-Likert scale ranging from one (completely untrue of self) to six (describes self perfectly). It was designed to assess the EMSs. Item examples are "During my childhood, nobody supported me when I was sad or scared" (emotional deprivation), "I am a failure" (fail to achieve) and "I have the feeling that the world is a dangerous place" (vulnerability to harm and illness). Administering the 205-item long version raises concerns about fatigue effects. In adult populations, the short and the long version of YSQ show comparable psychometric properties (Waller, Dickson, \& Ohanian, 2002). Therefore, the Korean short version of YSQ (Cho, 2001a; 2010b; 2002) consisting of 90 items was used. The Korean short version of YSQ demonstrates good psychometric properties (Cho, 2001a; $2001 b ; 2002)$. An individual schema score was obtained by averaging scores on the five items in each schema. Cronbach's alphas for the various subscales in the present study had raged from 0.56 to 0.89 .

\section{Inventory for Perceived PRBs}

The inventory for perceived PRBs was developed by Huh (2004) to assess the perceived PRBs: supervise, rational explanation, affection, inconsistency, over expectation, intrusiveness, abuse and neglect. It is consisted of 43 items rated on four-Likert scale (1= "No, never", 2 = "Yes, but seldom", 3 = "Yes, often", 4 = "Yes, most of the time"). In this study, Cronbach's alpha of the various subscales for father had rage from 0.70 to 0.86 and for mother had from 0.63 to 0.84 .

\section{Results}

\section{EMSs and Depression}

Correlations among EMSs, schema domains and depression are presented in Table 1. All EMSs are correlated with depression $(P<0.01)$. However, correlation under 0.3 is not significant in practice.

To investigate the unique contribution of EMSs to depression, regression analysis (stepwise) were performed. "Defectiveness/shame", "vulnerability to harm or illness", "failure" and "social isolation/alienation" made unique and significant contribution, together explaining up to $59 \%$ of the total depression variable ( $F=$ 78.75, $P<0.001$ ) (see Table 2).

\section{Perceived PRBs and EMS Domains}

In this study, the EMSs predicting depression were belong to "disconnection and rejection" and "impaired autonomy and performance" schema domains. Because we were interested in the relation between PRBs and schema domains which are relevant with depression, so we examined two domains. Correlations between PRBs and schema domains are presented in Table 3.

To investigate the unique contribution of PRBs to schema domains ("disconnection/rejection" and "impaired autonomy") which were related to depression, regression analysis was performed.

"Mother's neglect" and "father's intrusiveness" made unique and significant contribution, together explaining up to $30 \%$ of "disconnection/rejection" variable $(F=44.08, P<0.001)$ (see Table 4$)$.

"Mother's neglect" and "father's neglect" made unique and significant contribution, together explaining up to $24 \%$ of "impaired autonomy" variable $(F=33.45, P<0.001)$ (see Table 5). 
Table 1

Correlations Between EMSs, Schema Domains and Depression

\begin{tabular}{|c|c|}
\hline & Depression \\
\hline Disconnection/rejection & $0.70^{* *}$ \\
\hline abandonment & $0.59^{*}$ \\
\hline mistrust and abuse & $0.61^{* *}$ \\
\hline emotional deprivation & $0.52^{* *}$ \\
\hline defective/shame & $0.64^{* *}$ \\
\hline social isolation/alienation & $0.64^{* *}$ \\
\hline Impaired autonomy and performance & $0.73^{* *}$ \\
\hline dependence and incompetence & $0.61^{* *}$ \\
\hline vulnerability to harm or illness & $0.64^{* *}$ \\
\hline enmeshment & $0.46^{* *}$ \\
\hline failure to archive & $0.65^{* *}$ \\
\hline Impaired boundary & $0.49^{* *}$ \\
\hline entitlement and grandiosity & $0.27^{* *}$ \\
\hline insufficient self-control and self-discipline & $0.53^{* *}$ \\
\hline Orientation towards others & $0.46^{* *}$ \\
\hline subjugation & $0.63^{* *}$ \\
\hline self-sacrifice & $0.29^{* *}$ \\
\hline seek recognition/permission & $0.19^{* *}$ \\
\hline Excessive control & $0.50^{* *}$ \\
\hline pessimistic & $0.53^{* *}$ \\
\hline emotional inhibition & $0.48^{* *}$ \\
\hline unrelenting standards & $0.22^{* *}$ \\
\hline punishment & $0.32^{* *}$ \\
\hline
\end{tabular}

Note. ${ }^{* *} P<0.01$.

Table 2

Regression Analysis for Depression

\begin{tabular}{|c|c|c|c|c|c|c|c|c|}
\hline & Predicting variables & $\operatorname{Adj} . R^{2}$ & $d f$ & $F$ & $S E$ & $B$ & $\beta$ & $t$ \\
\hline Step 1. & defective/shame & 0.44 & 219 & $172.47^{* * *}$ & 0.664 & 1.36 & 0.66 & $13.13^{* * *}$ \\
\hline \multirow[t]{2}{*}{ Step 2.} & defective/shame & 0.53 & 218 & $126.73^{* * *}$ & 0.424 & 0.87 & 0.42 & $7.29^{* * *}$ \\
\hline & vulnerability to harm or illness & & & & 0.393 & 0.80 & 0.39 & $6.76^{* * *}$ \\
\hline \multirow[t]{3}{*}{ Step 3.} & defective/shame & 0.58 & 217 & $100.11^{* * *}$ & 0.235 & 0.48 & 0.24 & $3.43^{* *}$ \\
\hline & vulnerability to harm or illness & & & & 0.363 & 0.74 & 0.36 & $6.49^{* * *}$ \\
\hline & failure & & & & 0.294 & 0.59 & 0.29 & $4.71^{* * *}$ \\
\hline \multirow[t]{4}{*}{ Step 4.} & defective/shame & 0.59 & 216 & $78.75^{* * *}$ & 0.135 & 0.28 & 0.14 & 1.73 \\
\hline & vulnerability to harm or illness & & & & 0.325 & 0.66 & 0.33 & $5.71^{* * *}$ \\
\hline & failure & & & & 0.275 & 0.55 & 0.28 & $4.43^{* * *}$ \\
\hline & social isolation/alienation & & & & 0.180 & 0.36 & 0.18 & $2.60^{* *}$ \\
\hline
\end{tabular}

Notes. ${ }^{* *} P<0.01 ;{ }^{* * *} P<0.001$. 
Table 3

Correlations Between PRBs and Schema Domains

\begin{tabular}{|c|c|c|c|c|}
\hline & & & \multicolumn{2}{|c|}{ Maladaptive schema domains } \\
\hline & & & Disconnection/rejection & Impaired autonomy and performance \\
\hline \multirow{8}{*}{$\begin{array}{l}\text { PRBs } \\
\text { (Father) }\end{array}$} & \multirow{3}{*}{ Positive } & Supervise & $-0.16^{*}$ & -0.08 \\
\hline & & Rational Explanation & $-0.23^{* *}$ & $-0.22^{* *}$ \\
\hline & & Affection & $-0.27^{* * *}$ & $-26^{* * *}$ \\
\hline & \multirow{5}{*}{ Negative } & Inconsistency & $0.27^{* * *}$ & $0.29^{* * *}$ \\
\hline & & Over Expectation & $0.16^{*}$ & $0.17^{*}$ \\
\hline & & Intrusiveness & $0.27^{* * *}$ & $0.32^{* * *}$ \\
\hline & & Abuse & $0.26^{* * *}$ & $0.27^{* * *}$ \\
\hline & & Neglect & $0.47^{*}$ & $0.36^{* * *}$ \\
\hline \multirow{8}{*}{$\begin{array}{l}\text { PRBs } \\
\text { (Mother) }\end{array}$} & \multirow{3}{*}{ Positive } & Supervise & -0.15 & -0.09 \\
\hline & & Rational Explanation & -0.19 & -0.20 \\
\hline & & Affection & $-0.30^{* * *}$ & $-0.26^{* * *}$ \\
\hline & \multirow{5}{*}{ Negative } & Inconsistency & 0.20 & 0.23 \\
\hline & & Over Expectation & 0.15 & 0.14 \\
\hline & & Intrusiveness & $0.21^{* *}$ & $0.27^{* * *}$ \\
\hline & & Abuse & $0.31^{* * *}$ & $0.24^{* * *}$ \\
\hline & & Neglect & $0.53^{* * *}$ & $0.43^{* * *}$ \\
\hline
\end{tabular}

Notes. ${ }^{*} P<0.05 ;{ }^{* *} P<0.01 ;{ }^{* * *} P<0.001$.

Table 4

Regression Analysis for "Disconnection/Rejection"

\begin{tabular}{|c|c|c|c|c|c|c|}
\hline & & Predicting variables & $\operatorname{Adj} . R^{2}$ & $F$ & $\beta$ & $t$ \\
\hline \multirow{10}{*}{\multicolumn{2}{|c|}{ Enter }} & Fa. neglect & 0.30 & $9.94^{* * * *}$ & -0.28 & -0.85 \\
\hline & & Fa. intrusiveness & & & 0.52 & 1.60 \\
\hline & & Mo. neglect & & & 1.00 & $2.91^{* *}$ \\
\hline & & Mo. intrusiveness & & & -0.53 & -1.92 \\
\hline & & Fa. neglect $\times$ Mo. affection & & & 0.36 & 1.40 \\
\hline & & Fa. intrusiveness $\times$ Mo. affection & & & -0.39 & -1.16 \\
\hline & & Mo. neglect $\times$ Fa. affection & & & -0.75 & $-2.53^{*}$ \\
\hline & & Mo. intrusiveness $\times$ Fa. affection & & & 0.88 & $2.73^{* *}$ \\
\hline & & Mo. neglect $\times$ Fa. supervise & & & 0.21 & 1.01 \\
\hline & & Mo. intrusiveness $\times$ Fa. supervise & & & -0.28 & -1.20 \\
\hline \multirow{3}{*}{ Stepwise } & Step1 & Mo. neglect & 0.27 & $77.78^{* * *}$ & 0.53 & $8.8^{2^{* * *}}$ \\
\hline & \multirow{2}{*}{ Step2 } & Mo. neglect & 0.30 & $44.08^{* * *}$ & 0.49 & $8.25^{* * *}$ \\
\hline & & Fa. intrusiveness & & & 0.17 & $2.79^{* *}$ \\
\hline
\end{tabular}

Notes. Fa. $=$ father, Mo. $=$ mother; ${ }^{*} P<0.05,{ }^{* *} P<0.01,{ }^{* * *} P<0.001$.

There are a few interaction effects of mother's and father's PRBs in both models.

\section{Discussion}

In this study, we examined Young's (1994) EMS theory in depressive subjects. The aim was to identify the correlation between EMSs and depression in Korean subjects and examine the PRBs as predicting variables of schema domains associated with depression. The main results of this study are summarized as follows. First, correlations analysis among EMSs, schema domains and depression showed that most of EMSs are positively 
related to depression. To investigate the unique contribution of EMSs to depression, regression analysis was performed with EMSs as the predictors, and depression as the dependent variable. "Defectiveness/shame", "vulnerability to harm or illness", "failure to achieve" and "social isolation/alienation" made unique and significant contribution of total depression. EMSs were positively related to depression symptoms. Interestingly, each type of symptom was associated with a unique set of EMSs. For example, depression was predicted by "social undesirability", "mistrust/abuse" and "unrelenting standards" (Welburn, Coristine, Dagg, Pontefract, \& Jordan, 2002). Muris (2006) suggested that "social isolation/alienation", "mistrust and abuse", "failure to archive" and "unrelenting standards" predict depression. Therefore, maladaptive schema theory seems to be a useful concept to explain depression. Some similarity and difference can be found compared with the current study. In this study applied to Korean, "defectiveness/shame" and "vulnerability to harm or illness" were included as depression-predicting EMSs. It suggested that the social context and culture can effect to develop the EMSs. These EMSs can provide insight for patterns of thoughts and behaviors to clients.

Table 5

Regression Analysis for "Impaired Autonomy"

\begin{tabular}{|c|c|c|c|c|c|c|}
\hline & & Predicting variables & $\operatorname{Adj} . R^{2}$ & $F$ & $\beta$ & $t$ \\
\hline \multirow{10}{*}{\multicolumn{2}{|c|}{ Enter }} & Fa. neglect & 0.23 & $7.20^{* * *}$ & -0.27 & -0.78 \\
\hline & & Fa. intrusiveness & & & 0.39 & 1.15 \\
\hline & & Mo. neglect & & & 0.80 & $2.25^{*}$ \\
\hline & & Mo. intrusiveness & & & -0.25 & -0.86 \\
\hline & & Fa. neglect $\times$ Mo. affection & & & 0.26 & 0.95 \\
\hline & & Fa. intrusiveness $\times$ Mo. affection & & & -0.23 & -0.64 \\
\hline & & Mo. neglect $\times$ Fa. affection & & & -0.51 & -1.68 \\
\hline & & Mo. intrusiveness $\times$ Fa. affection & & & 0.48 & 1.41 \\
\hline & & Mo. neglect $\times$ Fa. supervise & & & 0.12 & 0.55 \\
\hline & & Mo. intrusiveness $\times$ Fa. supervise & & & -0.07 & -0.30 \\
\hline \multirow{3}{*}{ Stepwise } & Step1 & Mo. neglect & 0.18 & $45.23^{* * *}$ & 0.43 & $6.73^{* * *}$ \\
\hline & \multirow{2}{*}{ Step2 } & Mo. neglect & 0.24 & $33.45^{* * *}$ & 0.38 & $6.19^{* * *}$ \\
\hline & & Fa. neglect & & & 0.26 & $4.23^{* * *}$ \\
\hline
\end{tabular}

Notes. Fa. $=$ father, Mo. $=$ mother; ${ }^{*} P<0.05 ;{ }^{* *} P<0.01 ;{ }^{* * *} P<0.001$.

Second, in this study, the EMSs predicting depression belongs to "disconnection and rejection" and "impaired autonomy and performance" schema domains. These results are consistent with that of Halvorsen et al. (2009) and Haffart et al. (2005). According to Young (1990), a child's enduring experience of not getting his or her basic emotional needs met in relationship with significant others will give rise to the development of EMSs. To examine the notion, we analyzed the correlation between PRBs and schema domains. Most of PRBs showed a correlation with schema domains associated with depression. To investigate the unique contribution of PRBs to schema domains especially "disconnection/rejection" and "impaired autonomy", regression analysis was performed. "Mother's neglect" and "father's intrusiveness" made unique and significant contribution to "disconnection/rejection" variable. "Mother's neglect" and "father's neglect" made unique and significant contribution to "impaired autonomy" variable. However, it is important to note that PRBs only explained a restricted proportion (maximally 30\%) of EMSs. There are a few interaction effects of mother's and father's PRBs in both models. Future studies should examine the temperament and the toxic interaction with other family members and peers. 
It should be mentioned that the current study has limitations. First, this study relied on a sample of non-clinical group. It would be interesting to study clinical sample. The current results may or may not generalize to clinical group. However, Rijkeboer and van den Bergh (2006) demonstrated that EMSs are comparables in clinical and non-clinical samples. As EMSs can be regard as a dimensional instead of a categorical construct, we think that our findings might be translatable to clinical samples. Second, the sample is consisted of young adults. It is clear that many types of Axis I and Axis II disorder have their origins during childhood. Longitudinal studies are needed for investigating the proposed causal relationship of EMSs, temperament and PRBs to depression.

Nevertheless, the current findings are well in keeping with Young's (1994) theory in Korean depressed subjects. It is clear that EMSs play a prominent role in the psychological symptom. The effect sizes of antidepressant and cognitive therapy are moderate (Lipsey \& Wilson, 1993; Westen \& Morrison, 2001; Walsh, Seidman, Sysko, \& Gould, 2002). Depression would recurrent if vulnerability for depression will not discard. Therefore, personality trait, such as self-directedness and insight for maladaptive schemas, is important (Clonginger, Svrakic, \& Przybeck, 2006; Halvorsen et al., 2009). The schema theory can be useful for intervention. The research has demonstrated that old schemas are not wiped out, but that therapy leads to the activation of new or more adaptive schemas (e.g., Bouton, 2004). As schema-related contexts may reactivate the dormant schemas, it might be important to develop treatment strategies that help client to cope with depression. These new schemas might result from new experiences in interaction with an accepting therapist and new experiences due to a better and more compassionate understanding of previous negative interaction with the parent or caregivers.

\section{References}

Andrade, L., Caraveo-Anduage, J. J., Berglund, P., Bijl, R. V., De Graaf, R., Vollebergh, W., .., Wittchen (2003). The epidemiology of major depressive episodes: Results from the ICPE (International Consortium of Psychiatric Epidemiology) Surveys. International Journal of Methods in Psychiatric Research, 12, 3-21.

Beck, A. T. (1967). Depression: Causes and treatment. Philadelphia: University of Pennsylvania Press.

Beck, A. T. (1976). Cognitive therapy and the emotional disorders. New York: International Universities Press.

Beck, A. T. (1987). Cognitive models of depression. Journal of Cognitive Psychotherapy, 1, 2-27.

Baker, E., \& Beech, A. R. (2004). Dissociation and variability of adult attachment dimensions and early maladaptive schemas in sexual and violent offenders. Journal of Interpersional Violence, 19, 1119-1136.

Bosmans, G., Braet, C., \& Vlierberghe, L. V. (2009). Attachment and symptoms of psychopathology: Early maladaptive schemas as a cognitive link? Clinical Psychology and Psychotherapy, online in Wiley InterScience. DOI:10.1002/cpp.667.

Bouton, M. E. (2004). Context and behavioral processes in extinction. Learning and Memory, 11, 485-494.

Cloninger, C. R., Svrakic, D. M., \& Przybeck, T. R. (2006). Can personality assessment predict future depression? A twelve-month follow-up of 631 subjects. Journal of Affective Disorders, 92(1), 35-44.

Cukor, D. (2004). The relation among parenting patterns, childhood events and cognitive schema. Dissertation Abstracts International: Section B: Science and Engineering, 65, 432.

Cho, S. H. (2001a). Factor structure of the Korean version of schema questionnaire. The Korean Journal of Counseling and Psychotherapy, 13(1), 177-192.

Cho, S. H. (2001b). Early maladaptive schemas, defense styles and interpersonal relationships. The Korean Journal of Counseling and Psychotherapy, 13(3), 39-54.

Cho, S. H. (2002). Early maladaptive schemas and psychological unadjustment. The Korean Journal of Counseling and Psychotherapy, 14, 775-788.

Delattre, V., Servant, D., Rusinek, S., Lorette, C., Parquet, P. J., Goudemand, M., \& Hautekeete, M. (2004). The early maladaptive schemas: A study in adult patients with anxiety disorders. Encephale, 30(3), 255-258.

Haffart, A., Sexton, H., Hedley, L. M., WANG, C. E., Holthe, H., Haugum, J. A., ..,, Holte, A. (2005). The structure of maladaptive schemas: A confirmatory factor analysis and a psychometric evaluation of factor-derived scales. Cognitive Therapy and Research, 29, 627-644. 
Harris, A., \& Curtin, L. (2002). Parental perceptions, early maladaptive schemas, and depressive symptoms in young adults. Cognitive Therapy Research, 26, 405-416.

Halvorsen, M., WANG, C. E., Richter, J., Myrland, I., Pedersen, S. K., Eisemann, M., \& Waterloo, K. (2009). Early maladaptive schemas, temperament and character traits in clinically depressed and previously depressed subjects. Clinical Psychology and Psychotherapy, 16, 394-407.

Hinrichsen, H., Waller, G., \& Emanuelli, F. (2004). Social anxiety and agoraphovia in the eating disorders: Associations with core beliefs. Journal of Nervous and Mental Disease, 192, 784-787.

Huh, M. Y. (2004). A study for the development and malidation of an inventory for parenting behavior perceived by adolescents. The Korea Journal of Youth Counseling, 12(2), 170-189.

Ingram, R. E., \& Siegle, F. J. (2002). Contemporary methodological issue in the study of depression: Not your father's Oldsmobile. In I. H. Gotlib, \& C. L. Hammen (Eds), Handbook of depression (2nd ed., pp. 86-114). New York: The Guilford Press.

Kessler, R. C., Berglund, P., Demler, O., JIN, R., Koretz, D., Merikangas, K. R., ..., \& WANG. (2003). The epidemiology of major depressive disorder: Results from the NCS-R (National Comorbidity Survey Replication). The Journal of the American Medical Association, 289, 3095-3105.

Lee, Y. H., \& SONG, J. Y. (1991). A study of the reliability and the validity of the BDI, SDS and MMPI-D scales, Korean Journal of Clinical Psychology, 10(1), 98-113.

Lipsey, M. W., \& Wilson, D. B. (1993). The efficacy of psychological educational and behavioral treatment: Confirmation from meta-analysis. American Psychologist, 48, 1181-1209.

McGinn, L., Cukor, D., \& Sanderson, C. (2005). The relationships between parenting style, cognitive style and anxiety and depression: Does increased early adversity influence symptom severity though the mediation role cognitive style? Cognitive Therapy Research, 29, 219-242.

Meyer, C., \& Gillings, K. (2004). Parental bonding and bulimic psychopathology: The mediating role of mistrust/abuse beliefs. International Journal of Eating Disorders, 35, 229-233.

Muris, M. (2006). Maladaptive schemas in non-clinical adolescents: Relations to perceived parental rearing behaviors, big five personality factors and psychopathological symptoms. Clinical Psychology and Psychotherapy, 13, 405-413.

Rijkeboer, K. J., \& van den Bergh, H. (2006). Multiple group confirmatory factor analysis of the Young schema-questionnaire in a Dutch clinical versus non-clinical population. Cognitive Therapy and Research, 30, 263-278.

Sheffield, A., Waller, G., \& Emanuelli, F. (2006). Is comorbidity in the eating disorders related to perceptions of parenting? Criterion validity of the revised Young Parental Inventory. Eating Behaviors, 7, 37-45.

Schmitdt, N. B., Joiner, T. E. Jr., \& Young, J. E. (2004). Global maladaptive schemas, negative life events, and psychological distress. Journal of Psychopathology and Behavioral Assessment, 26(1), 65-72.

Schmitdt, N. B., Joiner, T. E. Jr., Young, J. E., \& Telch, M. J. (1995). The schema questionnaire: Investigation of psychometric properties and the hierarchical structure of a measure of early maladaptive schemas. Cognitive Therapy and Research, 19, 295-321.

Soygüt, G., \& Çakir, Z. (2009). The mediation role of the interpersonal schemas between parenting styles and psychological symptoms: A schema focused view. Turkish Journal of Psychiatry, 20(2), 144-152.

Young, J. E. (1990). Cognitive therapy of personality disorders: A schema-focused approach. Sarasota, F. L.: Professional Resource Press.

Young, J. E. (1994). Cognitive therapy for personality disorders: A schema-focused approach. Sarasota, F. L.: Professional Resource Press.

Young, J. E., \& Brown, G. (1990). Young schema questionnaire. New York: Cognitive Therapy Center of New York.

Young, J. E., Klosko, J. S., \& Weishaar, M. E. (2003). Schema therapy: A practitioner's guide. N. Y.: The Guilford Press.

Walsh, B. T., Seidman, S. N., Sysko, R., \& Gould, M. (2002). Placebo responses in studies of major depression: Variable, substantial, and growing. Journal of the American Medical Association, 287, 1840-1847.

Waller, G., Dickson, C., \& Ohanian, V. (2002). Cognitive content in bulimic disorders: Core beliefs and eating attitudes. Eating Behaviors, 3, 171-178.

Welburn, K., Coristine, M., Dagg, P., Pontefract, A., \& Jordan, S. (2002). The schema questionnaire-short form: Factor analysis and relationship between schemas and symptoms. Cognitive Therapy and Research, 26, 519-530.

Westen, D., \& Morrison, K. (2001). A multidimensional meta-analysis of treatments for depression, panic, and generalized anxiety disorder: An empirical examination of the status of empirically supported therapies. Journal of Consulting and Clinical Psychology, 69, 875-899.

Wright, M. O., Crawford, E., \& Del Castillo, D. (2009). Childhood emotional maltreatment and later psychological distress among college students: The mediating role of maladaptive schemas. Child Abuse Neglect, 33(1), 59-68. 